\title{
Low prevalence of Merkel cell polyomavirus with low viral loads in oral and maxillofacial tumours or tumour-like lesions from immunocompetent patients: Absence of Merkel cell polyomavirus-associated neoplasms
}

\author{
SHUNSUKE TANIO $^{1,2}$, MICHIKO MATSUSHITA ${ }^{2}$, SATOSHI KUWAMOTO ${ }^{2}$, YASUSHI HORIE ${ }^{3}$, \\ ISAMU KODANI $^{1}$, ICHIRO MURAKAMI ${ }^{2}$, KAZUO RYOKE $^{1}$ and KAZUHIKO HAYASHI ${ }^{2}$ \\ ${ }^{1}$ Division of Oral and Maxillofacial Biopathological Surgery, Department of Medicine of Sensory and Motor Organs, \\ Faculty of Medicine; ${ }^{2}$ Division of Molecular Pathology, Department of Pathology, Tottori University, \\ Yonago, Tottori 683-8503; ${ }^{3}$ Department of Anatomic Pathology, Faculty of Medicine, \\ Tottori University, Yonago, Tottori 683-8504, Japan
}

Received April 23, 2015; Accepted July 30, 2015

DOI: $10.3892 / \mathrm{mco} .2015 .629$

\begin{abstract}
It was recently demonstrated that $\sim 80 \%$ of Merkel cell carcinomas (MCCs) harbour a novel polyomavirus, Merkel cell polyomavirus (MCPyV). $\mathrm{MCPyV}$ has been detected in various human tissue samples. However, previous studies on the prevalence of MCPyV in oral tumours or tumour-like lesions are incomplete. To address this issue, we measured MCPyV DNA quantity using quantitative polymerase chain reaction (qPCR) in 327 oral tumours or tumour-like lesions and 54 jaw tumours or cyst lesions from 381 immunocompetent patients, as well as in 4 oral lesions from 4 immunosuppressed patients. qPCR revealed a low MCPyV prevalence $(25 / 381,6.6 \%)$ with low viral loads (0.00024-0.026 copies/cell) in oral and maxillofacial tumours and tumour-like lesions from immunocompetent patients. The prevalence was $7 / 176(4.0 \%)$ in invasive squamous cell carcinomas (SCCs) [2/60 (3.33\%) SCCs of the tongue, 4/52 (7.7\%) SCCs of the gingiva and 1/19 (5.3\%) SCCs of the floor of the mouth], 1/10 (10\%) in dysplasias, 1/5 (20\%) in adenocarcinomas, $2 / 13(15.4 \%)$ in adenoid cystic carcinomas, $1 / 10(10 \%)$ in non-Hodgkin's lymphomas, 3/10 (30\%) in lipomas, $3 / 5$ (60\%) in neurofibromas, 1/3 (33.3\%) in Schwannomas, $2 / 12(16.7 \%)$ in Warthin's tumours, $2 / 11(18.2 \%)$ in pyogenic granulomas, $1 / 14(7.1 \%)$ in radicular cysts and $1 / 12(8.3 \%)$ in ameloblastomas. The prevalence in lesions from immunosuppressed patients $(1 / 4,25 \%)$ was higher compared
\end{abstract}

Correspondence to: Dr Shunsuke Tanio or Professor Kazuhiko Hayashi, Division of Molecular Pathology, Department of Pathology, Tottori University, 86 Nishi-cho, Yonago, Tottori 683-8503, Japan

E-mail: s-tanio@med.tottori-u.ac.jp

E-mail: hayashik@med.tottori-u.ac.jp

Key words: Merkel cell polyomavirus, oral cavity tumour, jaw tumour, quantitative polymerase chain reaction with that in lesions from immunocompetent patients $(25 / 381$, $6.6 \%$ ), but the difference was not statistically significant. To the best of our knowledge, this study was the first to report prevalence data of MCPyV in tumours and cysts of the jaws $(2 / 54,3.7 \%)$. These data indicated absence of MCPyV-related tumours or tumour-like lesions in the oral cavity and jaws and suggested that the detected MCPyV DNA was derived from non-neoplastic background tissues with widespread low-level $\mathrm{MCPyV}$ infection.

\section{Introduction}

Merkel cell polyomavirus (MCPyV) was recently discovered to be associated with Merkel cell carcinoma (MCC), a rare and aggressive type of human skin cancer (1). MCPyV-induced oncogenesis is considered to be involved in the transformative properties of the MCPyV large T antigen. MCPyV has been detected in MCC patients and appears to play a key role in tumourigenesis; $~ 80 \%$ of MCCs harbour MCPyV (1). Using quantitative polymerase chain reaction (qPCR), MCPyV has been detected in malignant and benign tumours (1-16). Moreover, certain investigators have reported that low viral loads of MCPyV have also been detected in normal human tissue samples, including skin, liver and respiratory secretions, suggesting that this virus is widespread in the human body $(7,17)$. However, previous studies on the frequency of MCPyV infection in oral tumours or tumour-like lesions are partial and incomplete $(7,15)$. High viral loads of MCPyV were detected in all saliva samples from 10 patients without cancer (7).

In previous studies conducted by Hashida et al (16) and Pantulu et al (18), MCPyV was found to be associated with the pathogenesis of non-small-cell lung cancer and chronic lymphocytic leukemia.

The aim of this study was to determine the prevalence of MCPyV and identify new MCPyV-related tumours or tumour-like lesions in the maxillofacial region, in addition 
Table I. Merkel cell polyomavirus (MCPyV) detection in tumours or tumour-like lesions from the oral cavity and jaws of immunocompetent patients using quantitative polymerase chain reaction (qPCR).

\begin{tabular}{|c|c|c|c|}
\hline Types of lesions & Case no. & $\begin{array}{l}\text { Prevalence, } \\
\text { no./total }(\%)\end{array}$ & $\begin{array}{l}\text { MCPyV DNA load } \\
\text { (copies/cell) }\end{array}$ \\
\hline \multicolumn{4}{|l|}{ Tumours or tumour-like lesions of the oral cavity } \\
\hline Invasive SCC & 176 & $7 / 176(4.0)$ & $0.00038-0.00097$ \\
\hline Common type & 155 & $7 / 155(4.5)$ & $0.00038-0.00097$ \\
\hline Tongue & 60 & $2 / 60(3.33)$ & $0.00038-0.00097$ \\
\hline Gingiva & 52 & $4 / 52(7.7)$ & $0.00038-0.00092$ \\
\hline Buccal mucosa & 11 & $0 / 11$ & - \\
\hline Floor of the mouth & 19 & $1 / 19(5.3)$ & 0.00078 \\
\hline Palate & 9 & $0 / 9$ & - \\
\hline Lip & 4 & $0 / 4$ & - \\
\hline Variant type & 21 & $0 / 21$ & - \\
\hline Spindle cell carcinoma & 3 & $0 / 3$ & - \\
\hline Undifferentiated carcinoma (lymphoepithelial carcinoma) & 18 & $0 / 18$ & - \\
\hline $\mathrm{SCC}$ in situ & 3 & $0 / 3$ & - \\
\hline Dysplasia (leukoplakia with atypia) & 10 & $1 / 10(10.0)$ & 0.00066 \\
\hline Small-cell carcinoma & 1 & $0 / 1$ & - \\
\hline Adenocarcinoma & 5 & $1 / 5(20.0)$ & 0.00035 \\
\hline Mucoepidermoid carcinoma & 13 & $0 / 13$ & - \\
\hline Adenoid cystic carcinoma & 13 & $2 / 13(15.4)$ & $0.00040-0.00065$ \\
\hline Malignant pleomorphic adenoma & 5 & $0 / 5$ & - \\
\hline Malignant melanoma & 6 & $0 / 6$ & - \\
\hline Non-Hodgkin's lymphoma & 10 & $1 / 10(10.0)$ & 0.0021 \\
\hline Metastatic cancer ${ }^{\mathrm{a}}$ & 6 & $0 / 6$ & - \\
\hline Fibroma & 11 & $0 / 11$ & - \\
\hline Papilloma & 12 & $0 / 12$ & - \\
\hline Lipoma & 10 & $3 / 10(30.0)$ & $0.00083-0.026$ \\
\hline Neurofibroma & 5 & $3 / 5(60.0)$ & 0.00034-0.0015 \\
\hline Schwannoma & 3 & $1 / 3(33.3)$ & 0.00024 \\
\hline Pleomorphic adenoma & 14 & $0 / 14$ & - \\
\hline Warthin's tumour & 12 & 2/12 (16.7) & $0.00030-0.0039$ \\
\hline Pyogenic granuloma & 11 & 2/11 (18.2) & $0.000340-0.000345$ \\
\hline Epulis in a patient with $\mathrm{MCPyV}^{+} \mathrm{MCC}$ & 1 & $0 / 1$ & - \\
\hline Total & 327 & 23/327 (7.0) & $0.00024-0.026$ \\
\hline \multicolumn{4}{|l|}{ Tumours or cysts of the jaws } \\
\hline Radicular cyst & 14 & $1 / 14(7.1)$ & 0.00039 \\
\hline Dentigerous cyst & 10 & $0 / 10$ & - \\
\hline Keratocystic odontogenic tumour & 10 & $0 / 10$ & - \\
\hline Ameloblastoma & 12 & $1 / 12(8.3)$ & 0.00057 \\
\hline Ossifying fibroma & 3 & $0 / 3$ & - \\
\hline Fibrous dysplasia & 5 & $0 / 5$ & - \\
\hline Total & 54 & $2 / 54(3.7)$ & $0.00039-0.00057$ \\
\hline Total & 381 & 25/381 (6.6) & $0.00024-0.026$ \\
\hline
\end{tabular}

${ }^{a}$ One case each of esophageal, gastric, renal and prostate cancer and 2 cases of lung cancer. MCC, Merkel cell carcinoma; SCC, squamous cell carcinoma.

to the oral region. Thus, we measured the MCPyV DNA quantity using qPCR in 327 oral tumours or tumour-like lesions, 54 jaw tumours or cyst lesions and 4 oral lesions from 4 immunosuppressed patients. 
Table II. MCPyV detection by qPCR in tumours or tumour-like lesions from immunosuppressed patients.

\begin{tabular}{lccc}
\hline Tumour and tumour-like lesions & No. of cases & $\begin{array}{c}\text { Prevalence, } \\
\text { no./total (\%) }\end{array}$ & $\begin{array}{c}\text { MCPyV DNA load } \\
\text { (copies/cell) }\end{array}$ \\
\hline Dysplasia from bone marrow transplant patient & 1 & $0 / 1$ & - \\
Papilloma from bone marrow transplant patient & 1 & $1 / 1(100.0)$ & 0.0003 \\
Ulcer from bone marrow transplant patient & 1 & $0 / 1$ & - \\
Ranula from HIV patient & 1 & $0 / 1$ & 0.0003 \\
Total & 4 & $1 / 4(25.0)$ & - \\
\hline
\end{tabular}

qPCR, quantitative polymerase chain reaction; MCPyV, Merkel cell polyomavirus; HIV, human immunodeficiency virus.

\section{Materials and methods}

Human tissue samples. The analysed samples comprised 385 of 404 formalin-fixed and paraffin-embedded (FFPE) samples, including 381 immunocompetent and 4 immunocompromised cases (Tables I and II). A total of 19 samples were excluded, due to lack of detection of the protein tyrosine phosphatase receptor type G. The 404 samples were obtained from 398 individuals who underwent biopsy or surgical resection of tumours or tumour-like lesions of the oral region at the Division of Oral and Maxillofacial Biopathological Surgery and the Department of Otolaryngology, Head and Neck Surgery of Tottori University Hospital, Japan, between April, 2003 and March, 2013.

The 381 immunocompetent cases were as follows: 155 common-type invasive squamous cell carcinomas (SCCs) (60 of the tongue, 52 of the gingiva, 11 of the buccal mucosa, 19 of the floor of the mouth, 9 of the palate and 4 of the lip), 21 variant-type invasive SCCs (3 spindle cell carcinomas and 18 undifferentiated carcinomas), 3 SCCs in situ, 10 dysplasias, 1 small-cell carcinoma, 5 adenocarcinomas, 13 mucoepidermoid carcinomas, 5 malignant pleomorphic adenomas, 6 malignant melanomas, 10 non-Hodgkin's lymphomas, 6 metastatic cancers (1 case each of esophageal, gastric, renal and prostate cancer, and 2 cases of lung cancer), 11 fibromas, 12 papillomas, 10 lipomas, 5 neurofibromas, 3 Schwannomas, 14 pleomorphic adenomas, 12 Warthin's tumours, 11 pyogenic granulomas, 1 epulis from an MCPyV-positive MCC patient, 14 radicular cysts, 10 dentigerous cysts, 10 keratocystic odontogenic tumours, 12 ameloblastomas, 3 ossifying fibromas and 5 fibrous dysplasias.

The 4 immunocompromised cases included 1 dysplasia from a bone marrow transplant patient, 1 papilloma from a bone marrow transplant patient, 1 ulcer from a bone marrow transplant patient and 1 ranula from an HIV-positive patient.

The study protocol was approved by the Institutional Review Board of the Faculty of Medicine, Tottori University.

qPCR. DNA was extracted from each sample. Tumour samples sectioned into $10-\mu \mathrm{m}$ slices were excised into three pieces. DNA was extracted from each sample using the QIAamp DNA FFPE Tissue kit and Mini kit (Qiagen, Hilden, Germany) according to the manufacturer's instructions. The presence of adequate DNA in the samples was confirmed by measuring the internal control DNA of RNase P. To determine the MCPyV
DNA quantity [relative ratio to MCPyV DNA (1.0 copy/cell) from the reference $\mathrm{MCC}$ ] for each case, qPCR was performed using an ABI PRISM 7900HT Sequence Detection system (Applied Biosystems, Foster City, CA, USA). A total of $30 \mathrm{ng}$ of each DNA sample were amplified using $5 \mu \mathrm{l}$ of Express qPCR Supermix with Premixed ROX (Invitrogen, Carlsbad, CA, USA), $240 \mathrm{nmol} / 1$ fluorescein-labelled locked nucleic acid hydrolysis probe 22 (5'-TGGTGGAG-3') from a Universal Probe Library (Roche Diagnostics, Basel, Switzerland) and $0.9 \mu \mathrm{mol} / \mathrm{l}$ primer in a final volume of $10 \mu \mathrm{l}$. The positive control was MCCs, whereas water was used as the negative control. Thermal cycling consisted of incubation for $2 \mathrm{~min}$ at $50^{\circ} \mathrm{C}$, with initial denaturation for $10 \mathrm{~min}$ at $95^{\circ} \mathrm{C}$, followed by 40 cycles of denaturation for $15 \mathrm{sec}$ at $95^{\circ} \mathrm{C}$ and annealing for $1 \mathrm{~min}$ at $60^{\circ} \mathrm{C}$, as previously described (19). The virus quantity was determined using the virus signal in a positive MCC sample as reference. Thresholds were plotted against each standard sample. All the reactions of samples and controls were performed in triplicate, and the average was described. The MCPyV DNA quantity in each sample was determined based on the corresponding standard curves.

\section{Results}

MCPyV DNA detection in tumours and tumour-like lesions in the oral cavity and jaws of immunocompetent patients. MCPyV DNA was quantified from the FFPE samples of 381 immunocompetent and 4 immunocompromised cases and the data are summarised in Tables I and II, respectively.

qPCR data for MCPyV DNA are shown for the positive control (Fig. 1A) and 2 representative cases (Fig. 1B and C). The range of the MCPyV DNA quantity was very low or low: 0.00024-0.026 copies/cell, with a median of 0.00053 copies/cell. The overall prevalence of MCPyV in tumours or tumour-like lesions of the oral cavity and jaws was 25/381 (6.6\%)

Prevalence of MCPyV in oral tumour or tumour-like lesions. The MCPyV prevalence in invasive SCCs was 7/176 (4.0\%) [2/60 (3.33\%) SCCs of the tongue, 4/52 (7.7\%) SCCs of the gingiva and $1 / 19(5.3 \%)$ SCCs of the floor of the mouth], $1 / 10(10 \%)$ in dysplasias, $1 / 5(20 \%)$ in adenocarcinomas, 2/13 (15.4\%) in adenoid cystic carcinomas, $1 / 10$ (10\%) in nonHodgkin's lymphomas, $3 / 10(30 \%)$ in lipomas, $3 / 5(60 \%)$ in neurofibromas, $1 / 3$ (33.3\%) in Schwannomas, $2 / 12(16.7 \%)$ in 


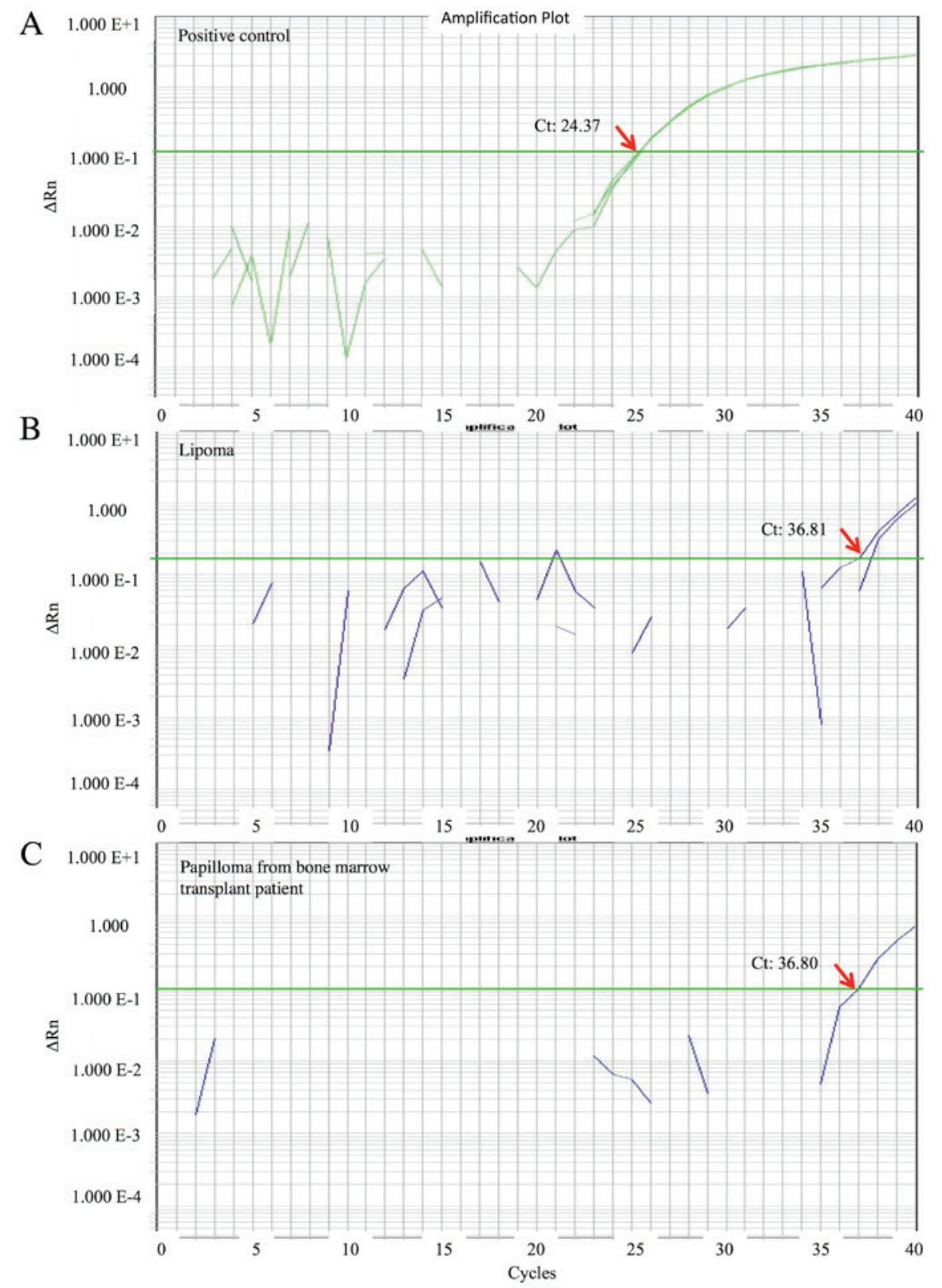

Figure 1. Representative data of quantitative polymerase chain reaction for Merkel cell polyomavirus DNA in (A) the positive control, (B) a lipoma case and (C) a papilloma from a patient with a bone marrow transplant. Amplification plot indicating $\mathrm{Ct}$ values. Ct, cycle threshold.

Warthin's tumours and 2/11 (18.2\%) in pyogenic granulomas. The MCPyV DNA (0.00083-0.026) in a case of lipoma was higher compared with that in other tumours or tumour-like lesions.

Prevalence of MCPyV in jaw tumours or cyst lesions. The MCPyV prevalence was $1 / 14(7.1 \%)$ in radicular cysts and $1 / 12(8.3 \%)$ ameloblastomas. No significant difference was observed between the MCPyV prevalence in tumours or tumour-like lesions of the oral cavity and that in tumours or cysts of the jaws (7.0 and $3.7 \%$, respectively; $\mathrm{P}=0.5537$ ).

MCPyV DNA detection in oral lesions from immunosuppressed patients. MCPyV DNA was detected in one case of papilloma from a bone marrow transplant patient but was not detected in the remaining 3 cases $(1 / 4,25 \%)$ (Table II).

\section{Discussion}

In this study, qPCR was used to investigate whether MCPyV was present in oral and maxillofacial tumours and tumour-like lesions. The possibility of contamination was unlikely, as ultrapure water-negative controls were consistently negative. Loyo et al (7) reported data on MCPyV DNA prevalence in oral cavity fresh-frozen materials $(51 / 67,76 \%)$; the prevalence was 19/47 SCCs, 2/10 normal mucosal samples and 10/10 saliva samples from patients without cancer. Oral cavity samples had 0.026 copies/genome, while MCCs had an average of 10 copies/genome (range, 173-0.05 copies/genome) and saliva had an average of 0.128 copies/genome (range, 5-0.01) (7). Matsushita et al (17) did not detect MCPyV DNA in non-neoplastic tissues from 10 tongue samples and 2 salivary gland samples from FFPE sections of autopsy cases. The 
MCPyV prevalence in the present study was 7.0\% (23/327). Matsushita et al (17) and our study used FFPE samples for MCPyV quantification, whereas Loyo et al (7) used fresh-frozen tissues. This is a major reason for the differences between our data on prevalence and those reported by Loyo et al (7). Certain previous studies reported that MCPyV DNA detection in fresh-frozen tissues is more reliable compared with detection in FFPE samples (20-22).

In this study, low or very low levels of MCPyV DNA were present in a wide variety of oral and maxillofacial tumours and tumour-like lesions, while the reference MCC sample had 1 copy of MCPyV/cell. The MCPyV DNA ratio in oral and maxillofacial tumours and tumour-like lesions relative to the reference MCC ranged between 0.00024 and 0.026 , indicating that tumours and tumour-like lesions positive for MCPyV DNA had lower viral loads compared with those of the MCC sample. These very low MCPyV DNA quantities detected in this study suggest the absence of MCPyV-associated tumours or tumour-like lesions in the oral and maxillofacial regions, as the low detected levels of MCPyV DNA may be derived from background non-neoplastic tissues with mild MCPyV infection, rather than from neoplastic tissues.

Cutaneous SCC is the second most frequent type of skin cancer (23), and cervical SCC is the major type of uterine cervical cancer (14). In SCC of the skin or uterine cervix, absence or lower frequency of MCPyV has been detected compared with MCCs (9-14). Dworkin et al reported that MCPyV was present in 15\% cases of cutaneous SCCs from immunocompetent individuals; this indicates that the pathogenic relevance of MCPyV in SCC is unknown (9). Murakami et al reported that $\mathrm{MCPyV}$ was present in $13 \%$ cases of cutaneous SCCs from Japanese patients; this indicates that cutaneous SCC in Japanese patients is infrequently associated with MCPyV (13). Imajoh et al reported that MCPyV was present in $19 \%$ of cervical SCCs from Japanese patients; this suggested that MCPyV may be a cofactor of human papillomavirus for tumour initiation and/or progression (14).

Oral SCC is the major type of oral cancer. Loyo et al detected low levels of MCPyV DNA in 19/47 oral SCCs and suggested that MCPyV was derived from background tissues and was not associated with oral SCC.

In this study, the prevalence of MCPyV $(23 / 327,7.0 \%)$ in tumours or tumour-like lesions of the oral cavity was higher compared with that in tumours or cysts of the jaws $(2 / 54,3.7 \%)$. However, the difference was not statistically significant $(\mathrm{P}=0.5537$, Fisher's exact test).

Baez et al (15) reported that MCPyV was present in $36.7 \%$ samples of saliva and $21.4 \%$ oral tissue samples from immunosuppressed patients. In this study, MCPyV was present in $25 \%$ of immunosuppressed patients, which was compatible with the prevalence data of Baez et al (15). It is evident that our estimated prevalence $(1 / 4,25 \%)$ was higher compared with that for oral or jaw lesions from immunocompetent patients (25/381, 6.6\%; $\mathrm{P}=0.2448$, Fisher's exact test). In the present study, prevalence was investigated in only 4 cases from immunosuppressed patients. Therefore, further studies using a large number of cases are required.

In conclusion, the prevalence of MCPyV DNA in FFPE samples of oral and maxillofacial tumours and tumour-like lesions was estimated using qPCR, revealing a low MCPyV prevalence $(25 / 381,6.6 \%)$ with very low or low viral loads (0.00024-0.026 copies/cell) in oral and maxillofacial tumours and tumour-like lesions from immunocompetent patients, and also reconfirmed a high prevalence $(1 / 4,25 \%)$ in oral lesions from immunosuppressed patients. To the best of our knowledge, this study was the first to report prevalence data on MCPyV DNA in tumours and cysts of the jaws (2/54, 3.7\%). These data suggest that the detected MCPyV DNA was derived from non-neoplastic background tissues with widespread low-level MCPyV infection, and the presence of MCPyV-related tumourigenesis was not confirmed in oral and maxillofacial tumours and tumour-like lesions. However, these prevalence study data may provide valuable insights for further studies on MCPyV infection and MCPyV-related diseases in the oral and maxillofacial regions.

\section{Acknowledgements}

The present study was supported by the Japan Society for the Promotion of Science (a Grant-in-Aid for Scientific Research, no. 26460433). We would like to thank Professor H. Kitano (Department of Otolaryngology, Head and Neck Surgery, Tottori University) for kindly providing bioptic or surgically resected samples. We would also like to thank Professor E. Nanba and all other members of the Division of Functional Genomics, Research Centre for Bioscience and Technology, Tottori University, for their useful advice and excellent technical support.

\section{References}

1. Feng H, Shuda M, Chang Y and Moore PS: Clonal integration of a polyomavirus in human Merkel cell carcinoma. Science 319: 1096-1100, 2008.

2. Gaynor AM, Nissen MD, Whiley DM, Mackay IM, Lambert SB, Wu G, Brennan DC, Storch GA, Sloots TP and Wang D: Identification of a novel polyomavirus from patients with acute respiratory tract infections. PLoS Pathog 3: e64, 2007.

3. Bialasiewicz S, Lambert SB, Whiley DM, Nissen MD and Sloots TP: Merkel cell polyomavirus DNA in respiratory specimens from children and adults. Emerg Infect Dis 15: 492-494, 2009

4. Goh S, Lindau C, Tiveljung-Lindell A and Allander T: Merkel cell polyomavirus in respiratory tract secretions. Emerg Infect Dis 15: 489-491, 2009.

5. Katano H, Ito H, Suzuki Y, Nakamura T, Sato Y, Tsuji T, Matsuo K, Nakagawa $\mathrm{H}$ and Sata T: Detection of Merkel cell polyomavirus in Merkel cell carcinoma and Kaposi's sarcoma. J Med Virol 81: 1951-1958, 2009.

6. Foulongne V, Kluger N, Dereure O, Mercier G, Molès JP, Guillot B and Segondy M: Merkel cell polyomavirus in cutaneous swabs. Emerg Infect Dis 16: 685-687, 2010.

7. Loyo M, Guerrero-Preston R, Brait M, Hoque MO, Chuang A, Kim MS, Sharma R, Liégeois NJ, Koch WM, Califano JA, et al: Quantitative detection of Merkel cell virus in human tissues and possible mode of transmission. Int J Cancer 126: 2991-2996, 2010.

8. Teman CJ, Tripp SR, Perkins SL and Duncavage EJ: Merkel cell polyomavirus (MCPyV) in chronic lymphocytic leukemia/small lymphocytic lymphoma. Leuk Res 35: 689-692, 2011.

9. Dworkin AM, Tseng SY, Allain DC, Iwenofu OH, Peters SB and Toland AE: Merkel cell polyomavirus in cutaneous squamous cell carcinoma of immunocompetent individuals. J Invest Dermatol 129: 2868-2874, 2009.

10. Kassem A, Technau K, Kurz AK, Pantulu D, Löning M, Kayser G, Stickeler E, Weyers W, Diaz C, Werner M, et al: Merkel cell polyomavirus sequences are frequently detected in nonmelanoma skin cancer of immunosuppressed patients. Int J Cancer 125: 356-361, 2009. 
11. Reisinger DM, Shiffer JD, Cognetta AB Jr, Chang Y and Moore PS: Lack of evidence for basal or squamous cell carcinoma infection with Merkel cell polyomavirus in immunocompetent patients with Merkel cell carcinoma. J Am Acad Dermatol 63: 400-403, 2010.

12. Ridd $\mathrm{K}, \mathrm{Yu} \mathrm{S}$ and Bastian BC: The presence of polyomavirus in non-melanoma skin cancer in organ transplant recipients is rare. J Invest Dermatol 129: 250-252, 2009.

13. Murakami M, Imajoh M, Ikawa T, Nakajima H, Kamioka M, Nemoto Y, Ujihara T, Uchiyama J, Matsuzaki S, Sano S, et al: Presence of Merkel cell polyomavirus in Japanese cutaneous squamous cell carcinoma. J Clin Virol 50: 37-41, 2011.

14. Imajoh M, Hashida Y, Nemoto Y, Oguri H, Maeda N, Furihata M, Fukaya T and Daibata M: Detection of Merkel cell polyomavirus in cervical squamous cell carcinomas and adenocarcinomas from Japanese patients. Virol J 9: 154, 2012.

15. Baez CF, Guimarães MA, Martins RA, Zalona AC, Cossatis JJ, Zalis MG, Cavalcanti SM and Varella RB: Detection of Merkel cell polyomavirus in oral samples of renal transplant recipients without Merkel cell carcinoma. J Med Virol 85: 2016-2019, 2013

16. Hashida Y, Imajoh M, Nemoto Y, Kamioka M, Taniguchi A Taguchi T, Kume M, Orihashi K and Daibata M: Detection of Merkel cell polyomavirus with a tumour-specific signature in non-small cell lung cancer. Br J Cancer 108: 629-637, 2013.

17. Matsushita M, Kuwamoto S, Iwasaki T, Higaki-Mori $\mathrm{H}$, Yashima S, Kato M, Murakami I, Horie Y, Kitamura Y and Hayashi K: Detection of Merkel cell polyomavirus in the human tissues from 41 Japanese autopsy cases using polymerase chain reaction. Intervirology 56: 1-5, 2013.
18. Pantulu ND, Pallasch CP, Kurz AK, Kassem A, Frenzel L, Sodenkamp S, Kvasnicka HM, Wendtner CM and Zur Hausen A: Detection of a novel truncating Merkel cell polyomavirus large $\mathrm{T}$ antigen deletion in chronic lymphocytic leukemia cells. Blood 116: 5280-5284, 2010.

19. Kuwamoto S, Higaki H, Kanai K, Iwasaki T, Sano H, Nagata K, Kato K, Kato M, Murakami I, Horie Y, et al: Association of Merkel cell polyomavirus infection with morphologic differences in Merkel cell carcinoma. Hum Pathol 42: 632-640, 2011.

20. Foulongne V, Dereure O, Kluger N, Molès JP, Guillot B and Segondy M: Merkel cell polyomavirus DNA detection in lesional and nonlesional skin from patients with Merkel cell carcinoma or other skin diseases. Br J Dermatol 162: 59-63, 2010.

21. Touzé A, Gaitan J, Maruani A, Le Bidre E, Doussinaud A, Clavel C, Durlach A, Aubin F, Guyétant S, Lorette G, et al: Merkel cell polyomavirus strains in patients with merkel cell carcinoma. Emerg Infect Dis 15: 960-962, 2009.

22. Martel-Jantin C, Filippone C, Cassar O, Peter M, Tomasic G, Vielh P, Brière J, Petrella T, Aubriot-Lorton MH, Mortier L, et al: Genetic variability and integration of Merkel cell polyomavirus in Merkel cell carcinoma. Virology 426: 134-142, 2012.

23. Boukamp P: UV-induced skin cancer: Similarities - variations J Dtsch Dermatol Ges 3: 493-503, 2005 